\title{
Generative Learning and the Making of Ethical Space: Indigenizing Forest School Teacher Training in Wabanakik
}

\author{
Katalin Doiron Koller \& Kay Rasmussen
}

\begin{abstract}
Aвstract This reflection on community-driven research in process is written from the perspective of graduate student co-researchers collaborating with Wabanaki community coresearchers on a pilot project involving a Wabanaki and a non-Indigenous organization. Three Nations Education Group Inc. (TNEGI) represents three Wabanaki schools and communities in Northeast Turtle Island. The Child and Nature Alliance of Canada (CNAC) offers a Forest and Nature School Practitioner Course (FNSPC) for educators seeking to operate forest schools. These diverse organizations have developed a pilot FNSPC training for a group of TNEGI educators, with the purpose of Indigenizing the FNSPC. This is necessary to address the Eurocentric forest and nature school practices in Canada, which often fail to recognize the herstories, presence, rights, and diversity of Indigenous Peoples and places. TNEGI educators envision a land-based pedagogy that centers Wabanaki perspectives and merges Indigenous and Western knowledges. In the FNSPC pilot, the co-researchers generated course changes as they progressed through the pilot, decolonizing the content and format as they went. Developing this Indigenized version of the FNSPC will have far-reaching implications for the CNAC Forest School ethos and teacher training delivery. This essay maps our collaborative efforts thus far in creating an ethical research space within this Indigenous/non-Indigenous research initiative and lays out intentions for the road ahead.
\end{abstract}

KeyWords Indigenous, land-based pedagogy, community-driven, Indigenize, training, ethical space, generative learning

Transmitting knowledge through real-life experiences on the land, whether through observation, modelling, experimentation, ceremony, or storytelling, is central to Indigenous cosmologies and worldviews (Simpson, 2017; Tuck et al., 2014). In Canada, Indigenous knowledge transmission has faced tremendous pressure from colonial policies intended to disrupt intergenerational teachings, languages, cultures, and identities. Even now, when First Nations schools have greater power over education, communities are still beholden to assimilative policies stemming from the Indian Act's control of education. First Nations operating community-based, community-run schools receive their rightful operating funding from the federal government only under comparability to the provincial school system (Koller, 2015). Therefore, educators in Wabanaki First Nations schools often feel an implicit pressure to follow provincially mandated curriculum, instructional hours, and subjects using the Western 
pedagogies that informed their creation. This makes authentically practicing Indigenous landbased pedagogies in "provincially-comparable" school contexts challenging.

All too often, in this context, Indigenous educators find themselves feeling "stuck" in a four-walled building, within a rigid academic calendar, separated from the land and traditional teachings that invigorate Indigenous knowledges and worldviews. Indigenous Peoples of Turtle Island know that the land is our first teacher and that settler-colonial policies, particularly in education, work to sever Indigenous Peoples from their land-based identities to suppress Indigenous collective rights to the land (Battiste, 2013; Green, 2014; Simpson, 2017). Further exacerbating this purposeful suppression of Indigeneity is the lack of respect Western education systems implicitly and explicitly exhibit for play-based, student-led, experiential teaching, instead favouring industrial models of education that produce a 'standardized' model citizen (Simpson, 2017).

However, across Canada, there is a growing movement for outdoor education and Forest and Nature Schools (see Appendix A) that has become stronger throughout the pandemic. Although this form of education provides the framework for Canadian educators to take children on the land, we question how and if Euro-Canadian notions of outdoor, place-based education are compatible with Indigenous land-based pedagogies? The Wabanaki communitydriven project discussed herein seeks to unpack just what affinities and tensions exist when two diverse cosmologies converge in the context of land-based teaching. Are Euro-Canadian outdoor education programs attuned to Indigenous herstories, or do they continue to perpetuate colonial myths of terra nullius? What might a trans-systemic pedagogy of land-based education look like in the context of First Nations education in Wabanaki communities?

These were questions of interest for Three Nations Education Group Inc. (TNEGI) and their three-member schools. TNEGI is a regional management organization (RMO) and an alliance representing Elsipogtog, Esgenoopetitj, and Negotkuk First Nations' educational interests, the three largest Wabanaki communities in the colonial province of New Brunswick, Canada. In recent years, TNEGI teachers have expressed interest in land-based teaching to meld traditional ecological knowledge and experiential teaching methods with provincial curriculum requirements. Potentially, mainstream outdoor education discourses might be harnessed to help integrate the use of traditional Indigenous teaching approaches in ways compatible with Euro-Canadian curriculum. However, mainstream outdoor education might also be problematic, as it does not always adequately attend to colonial herstories, animated Indigenous presence, and reconciled futures. In other words, taking students outside is not equivalent to decolonizing or Indigenizing Canadian education systems (Tuck, et al., 2014). Alternatively, TNEGI envisions the revitalization of land-based pedagogy such that ancestral Wabanaki teachings are propagated on equal ground with Euro-Canadian environmental science, critical for co-creating new ways of living together (Kimmerer, 2013). TNEGI's understanding of land-based pedagogy reflects Simpson's (2017) view of the land as a teacher, the land as context, and the context as the curriculum. This theoretical and methodological conception of land as pedagogy informs TNEGI's efforts to Indigenize and reclaim outdoor education for their Wabanaki students, families, and educators. 
With this goal in mind, in 2019, TNEGI negotiated a partnership with the Child and Nature Alliance of Canada (CNAC) to pilot an Indigenous-led Forest and Nature School Practitioners Course (FNSPC), hereafter referred to as 'the Pilot.' The partnership stemmed from an agreement on the need to decolonize the FNSPC content to create a model conducive to Wabanaki lifelong learning. Both groups conceptualized this joint effort as a pilot to Indigenize the FNSPC teacher certification process and to provide an opportunity for community-driven, collaborative action-research. The process of Indigenization "centres a politics of [I]ndigenous identity and [I]ndigenous cultural action" to disrupt Eurocentric paradigms (Smith, 1999, p. 146). Importantly, the process of Indigenization cannot merely be an "adding on" to what already exists; rather, it must break down that which is pre-existing and in its place rebuild anew using an authentic balance of Indigenous and Western knowledges as a foundation. In other words, Indigenizing the FNSPC certification process required that Indigenous voices be privileged in the deconstructing of the Euro-Canadian premise of the course in favour of a pluriversal paradigm that recognizes many diverse ways of experiencing, understanding, and living in the world.

Below the co-authors working as co-researchers with the pilot introduce themselves. Then, transsystemic ethical space in this community-driven context is defined, and protocols for co-creating research with Indigenous schools, communities, and organizations are discussed. We then outline the pilot's design, including our research questions, methods, and progress to date. In the final sections, we juxtapose land and place based education, summarize CNAC's ongoing efforts to decolonize, and map-intended directions for ongoing collaborative research activities.

\section{Kay}

Boozhoo. Waabishki Binesikwe anishinaabe-izhinikaaz Atik dodem. Wiisaakodewikwe. Wabanaki onjibaa. Wauzhushk Onigum onjibaa. My name is White Thunderbird Woman of the Caribou Clan. My English name is Kay Rasmussen. I am a mixed-race woman of Mi'kmaq, Acadian, and European heritage. I grew up in Wauzhushk Onigum unceded territory within Treaty Three, also known as Kenora, Ontario. I hold a Master of Education for Change in Sustainability and Environmental Education from Lakehead University. Besides my work conducting community-based research, I teach for Seven Generations Education Institute within the Early Childhood Education diploma program, and I am an FNSPC facilitator with CNAC.

\section{Katalin}

Woliwon wela'ioq kösz merci Thank you, my name is Katalin, and I am a Programs and Services Manager with TNEGI. As a non-Indigenous, critical feminist scholar and an environmental justice activist, I too am intimately aware of the necessity of locating oneself in relation to other peoples and communities. I have lived in Wabanakik for most of my life. My matriarchal ancestors are French-Acadian settlers, and my patriarchal ancestors are Hungarian immigrants. I have been working with Wabanaki communities since 2009 and am also a doctoral candidate in the geography of societal change program at Carleton University. 
My privileged location requires an iterative, critical self-reflexivity as I travel the path of decolonizing my mind, body, and professional practice concerning the communities with which I collaborate. As coordinator of the TNEGI land-based education portfolio and a contributor to our research programme, I am in a position of power that necessitates careful attention to how I may inadvertently impact project directions, co-researcher experiences, and research findings with my own biases. To ensure I retain accountability to all my relations therein, I listen first and then listen some more before taking the next steps. Practicing listening as method is critical as we move collectively toward the shared creation of an "ethical space" within which the TNEGI Pilot occurs.

\section{Creation of "Ethical Space" Protocols}

The need for ethical space within research arises from the validity of contrasting viewpoints about the world. Ethical space is the concept of a neutral meeting place between contending worldviews and knowledge systems where respectful, reciprocal engagement can occur (Ermine, 2007). Such space allows for the collective uncovering of how values, behaviours, and intentions are primarily influenced by covert mainstream powers. Further, ethical space fosters a setting where individuals can move beyond their mental worlds and position themselves in respectful, reflective dialogue with others. This positionality is necessary because when research is founded on Eurocentric assumptions, standards, and methodologies, Indigenous knowledges and traditions are often marginalized, relegated to the sidelines, or made invisible altogether (Battiste, 2013; Donald, 2009). Generating ethical space within our communitydriven collaborative research is an essential step in unsettling the work of colonization and creating a safe space of sharing and connection that respects and values all knowledges equally.

Decolonizing colonial hierarchies of knowledge is particularly important to education, and Mi'kmaw scholar Marie Battiste (2013) calls on educators and researchers to generate ethical spaces that "confront the in-between space that connects Indigenous and Eurocentric knowledge systems" (p. 105). Identifying what has been excluded by colonial thought is an important starting point as it helps us to better understand underlying assumptions and places of potential merging. Ethical space challenges educators and researchers to develop "transsystemic analysis and methods - that is, reaching beyond two distinct systems of knowledge to create fair and just educational systems and experiences" (Battiste, 2013, p.103). For harmony to be achieved between Indigenous and Eurocentric thought, where one has often been held up as dominant or hegemonic and the other relegated to the margins through colonial violences, anti-colonial space must continually be held open for the resurgence of alternative ways of knowing. From this perspective, it is essential that research conducted within Indigenous communities by community and non-community members working as co-researchers be attuned to specific ethical protocols.

Protocols that informed the creation of ethical space for our collaborative research team include the principles of OCAP - Ownership, Control, Access, and Possession - which centre Wabanaki communities as the drivers and benefactors of the research (FNIGC, 2020). Additionally, the "4R's" of community-based participatory research with Indigenous Peoples 
— Respect, Relevance, Reciprocity, and Responsibility — are present as the pre-existing foundation of our longstanding working relationships, deeply embedded as we are with one another through our commitment to education, our schools, and our communities (Castleden et al., 2012, p. 162). As the organization in common, co-researchers agreed for TNEGI to hold and protect all "primary data." Research design and activities were decided upon and undertaken jointly by co-researchers, who include educators and Principals from TNEGI First Nations' schools, First Nations' Directors of Education, and First Nations' Chiefs. This is the first formal research project TNEGI has participated in; however, it has collaborated for many years to decolonize provincial curriculum and teacher training. Given this, an anticipated biproduct of this work is the formation of a TNEGI Research Ethics Protocol informed by the experience of community and non-community members in the pilot. To ensure accountability to First Nations' extended community members and leadership, the collaborative research team regularly reports research activities to the TNEGI Executive Board.

\section{The Three Nations Education Group Inc. Pilot}

Before entering this research partnership, TNEGI's Early Years Connections initiative had offered professional learning on land-based teaching for several years. Interest in land-based education peaked in 2018 when TNEGI educators began talking about the FNSPC. In response, TNEGI initiated discussions with CNAC about hosting a practitioner's course in one of their member communities. It was important to TNEGI that facilitators of Indigenous ancestry teach a course about land-based learning in the participating educators' spaces and that a sustained community of practice be nurtured based on trainer/trainee relationships. CNAC agreed and confirmed that they would respond to the unique needs of TNEGI participants when assessing outcomes. Furthermore, prior learning would be recognized and valued in performance measurements and could include community advocacy work.

Both organizations concluded that such a modified approach of the FNSPC was more appropriate as a pilot, and this research project was born. In addition to the initial five-day intensive training in May 2019, TNEGI approved funding to support the group's request to gather together regularly to workshop the course content, learn from knowledge keepers, and continue to build a community of land-based practitioners. For fifteen months following, we - the educator and graduate student co-researchers or TNEGI "Forest Family", as we have aptly named ourselves - met regularly via monthly conference calls and intermittent two-day gatherings. Since the onset of the pandemic, we have been unable to meet in person, yet we have continued to support one another through individual and group mentoring via video conferencing. In one case, the pandemic restrictions created an opportunity for those that had finished their FNSPC certification to open a land-based extra-curricular program in their community. Those still in the process of completion benefit from the lived experience of those who are successfully practicing amid strenuous Covid-19 restrictions.

From the beginning, the partners and co-researchers were interested in the following questions: 
1. How do we, as TNEGI educators/researchers, interpret the appropriateness of CNAC's Forest and Nature School Practitioners' Course format and content concerning integration of Wabanaki worldviews in land-based learning settings? 2. What methods, practices, and perspectives do we as Wabanaki educators/ researchers utilize while engaging in the process of decolonizing the Forest and Nature School Practitioners' Course? What do we, as TNEGI educators/ researchers create, reclaim, and dismantle in the decolonization process?

3. How can TNEGI Forest School Practitioners' experience contribute to the decolonization of pedagogy, curriculum, and school environments for First Nations students? How do these contributions relate to self-determination in education?

These questions arose naturally among the Forest Family and extended group of coresearchers. A critical, safe, ethical space was nurtured by all so that individual and group observations and experiences could be shared free from judgement. This safe space was possible in large part because of the existing relationships and communication pathways among us as co-researchers and our mutual respect for all voices around the circle.

As we embarked on the Forest and Nature School Practitioners Course, we reflected on the possibilities for change and the co-creation of alternative teaching options that would embrace Wabanaki perspectives and meet Western course expectations. We identified and implemented the adaptations we felt necessary to center our needs and values as Wabanaki learners and NonIndigenous educators of Wabanaki students. This generative learning method in community education foregrounds knowledge co-construction and diffuses power over content and implementation among co-researchers, while confronting established assumptions and biases (Ball \& Pence, 2006). Generative, collective learning enabled us to recognize the need for, and enact the change required, to create a safe, trans-systemic space in the moment of encounter. For instance, we decided we needed to be permitted to study the course materials and submit the corresponding assignments as a peer group, given the collective nature of our Wabanaki cosmologies related to knowledge creation and transmission.

We also identified changes to the FNSPC performance assessment methods that we felt would better allow us to demonstrate our collective knowledge and abilities. For instance, instead of individual, written essays, we concluded that individual or group personal reflections on our practice using audio, video, photography, storytelling, and/or prose would be equally valuable demonstrations of our capabilities. Similarly, we allowed each other space and autonomy to identify which outcomes our schools and communities might benefit from and responded to assignment requirements in those unique ways, rather than following standardized criteria more reflective of non-Indigenous, individualistic learning environments. Therefore, we adapted the format of learning and how our comprehension was measured to better correspond to the needs of ourselves as learners and educators in Wabanaki communities.

Likewise, generative steps towards Indigenizing the FNSPC content began with the fiveday, in-person, intensive training, which precedes the coursework and assignments. We gathered 
in the fields, sheltered in the forests, and healed together on the beaches of Esgenoopetitj First Nation in Mi'kma'ki. The Child Nature Alliance of Canada co-facilitators were both of Indigenous backgrounds and imbued each day with stories of their lived experiences teaching students on Treaty lands. Importantly, we worked hard to provide comfort to community knowledge holders and Elders who joined us on the land despite the cold, windy weather. As a result, the oral herstory and Mi'kmaw language of Esgenoopetitj were continuously present, as community members shared numerous stories within which we centred our learning reflections.

The five-day intensive was by far the most impactful experience of the course for our group. Afterward, many expressed a paradigm shift in understanding how educational outcomes might be accomplished outside a building's walls. In the months that followed, we workshopped the content of the FNSPC teachers' guidebook, collectively identifying concepts that might be enriched with Indigenous voices and expanding upon them with in-depth discussions about colonialism, Indigenous sovereignty, and community well-being. Although the pandemic has prevented us from meeting in person the past year, when we can, we plan to come together again on the land to share and reflect upon our interconnected FNSPC journey. In particular, we will unpack how we have proceeded to integrate our land-based teaching approaches in the Westernized educational environment and what has been the result of our recentring of Wabanaki land-based pedagogies toward colonial curriculum outcomes. We hope to use narrative methods for capturing these reflections, including storytelling, sharing circles, and meditative group nature walks.

Our collective knowledge generation is a living endeavour framed by relational accountability to the land and all our relations. As we examine below relational accountability is core to our ongoing work as we strive to balance Euro-centric place-based education with authentic, Wabanaki land-based pedagogies.

\section{Land and Place in the Child and Nature Alliance of Canada Teacher Training}

Creating an ethical space for the intersection of Euro-Canadian place-based education and Indigenous land-based knowledge systems is to unsettle the work of settler colonization. Challenging and provocative questions must be considered which counter the business-asusual of everyday life and environmental education practice (Ashton, 2015; Taylor \& PaciniKetchabaw, 2015; Tuck \& Yang, 2012). An ethical space that welcomes reinhabitation, refiguring presence, and restorying can help develop an understanding of colonial identities relative to land (Calderon, 2014; Greenwood, 2011; Gruenewald, 2003; Nxumalo, 2019). In turn, this space encourages settler-dominant organizations, like CNAC, to begin to understand their own identity within place. Before the pilot with TNEGI, CNAC had done little to consider the pedagogical ways in which the FNSPC failed to teach about the land through an Indigenous lens to counter settler-colonial narratives of place. Although the name 'Forest and Nature School' implies that learning only occurs within a forest area, Indigenous land must be viewed as all-encompassing. No matter where people are in Canada, they are on Indigenous lands. With each step we take in life, we walk with and on the land. The land is alive, and its teachings are not confined to place. 
Although the current FNSPC in Canada has undergone multiple revisions since its release in 2013, in 2021, the course content remains heavily colonial and Euro-Canadian. There are ways in which the Euro-Canadian knowledge of the FNSPC comes alongside Indigenous knowledges in a compatible way, such as the use of sharing circles and storytelling to build understanding. However, based on the current Forest and Nature School model in Canada, the two knowledge systems are still disconnected, leading to tensions. For example, the CNAC ethos encourages Canadian educators, primarily of settler heritage, to access and use Indigenous lands without recognizing Indigenous epistemologies in a meaningful way (CNAC, 2019).

Therefore, we listen as Battiste (2013) calls on educators to consider what is excluded within the far-reaching assumptions of Eurocentric curriculum. Considering how an Indigenous narrative of land and place has been excluded from CNAC's FNSPC makes apparent how the content is contributing to the continued colonization of land and place within Canada. We acknowledge that although the FNSPC content has been heavily Eurocentric up until now, CNAC is currently taking essential steps towards decolonizing their practice. Such steps include building relationships with Indigenous communities, calling on and listening to the guidance of Indigenous Elders, Knowledge Holders, and staff through the formation of an Indigenous advisory committee, implementing staff training that centers Indigenous landbased pedagogies, decolonizing hiring processes through the holding of space for diverse peoples and ways of knowing, and altering funding models to reflect adequate pay and honoraria for Indigenous Elders and Knowledge Holders. The ethical space that CNAC is working to define has been significantly influenced by TNEGI and the Forest Family's voices.

\section{The Path Ahead}

Co-researchers continue to analyze the information garnered through the generative learning model. However, much of the pilot's qualitative data collection was planned to take place in the spring and summer of 2020 through land-based group reflection within the Forest Family's ethical space. Due to the onset of the global pandemic, in-person gatherings are on hold to mitigate the disproportionate risk of coronavirus transmission and trauma posed to Indigenous communities. Once this risk has passed, in-person knowledge sharing will resume, and narrative experiences from the pilot will be documented and analyzed by the co-authors for review by the co-researchers. In the interim, several Forest Family members have already begun the process of educational resource development with TNEGI's support, the outcomes of which will be shared widely, potentially contributing to the FNSPC's Indigenization.

Once the research is completed, a report of findings and recommendations will be made to extended co-researcher relations, including schools, communities, and organizations. Upon receipt of the research report, it is anticipated that project partners will continue to build on the pilot's efforts to further Indigenize land-based teaching in Indigenous contexts. TNEGI will harness the findings to continue developing Wabanaki land-based pedagogy in provincially comparable schools and to aid the Forest Family in mentoring other educators. CNAC will gain insight into how it might further decolonize its teacher training and pedagogical content. At the same time, both partners will continue to work together to sustain a community of Wabanaki 
land-based practitioners led by the Forest Family. These united efforts could have far-reaching implications that disrupt the transmission of coloniality and revitalize Indigenous pedagogies.

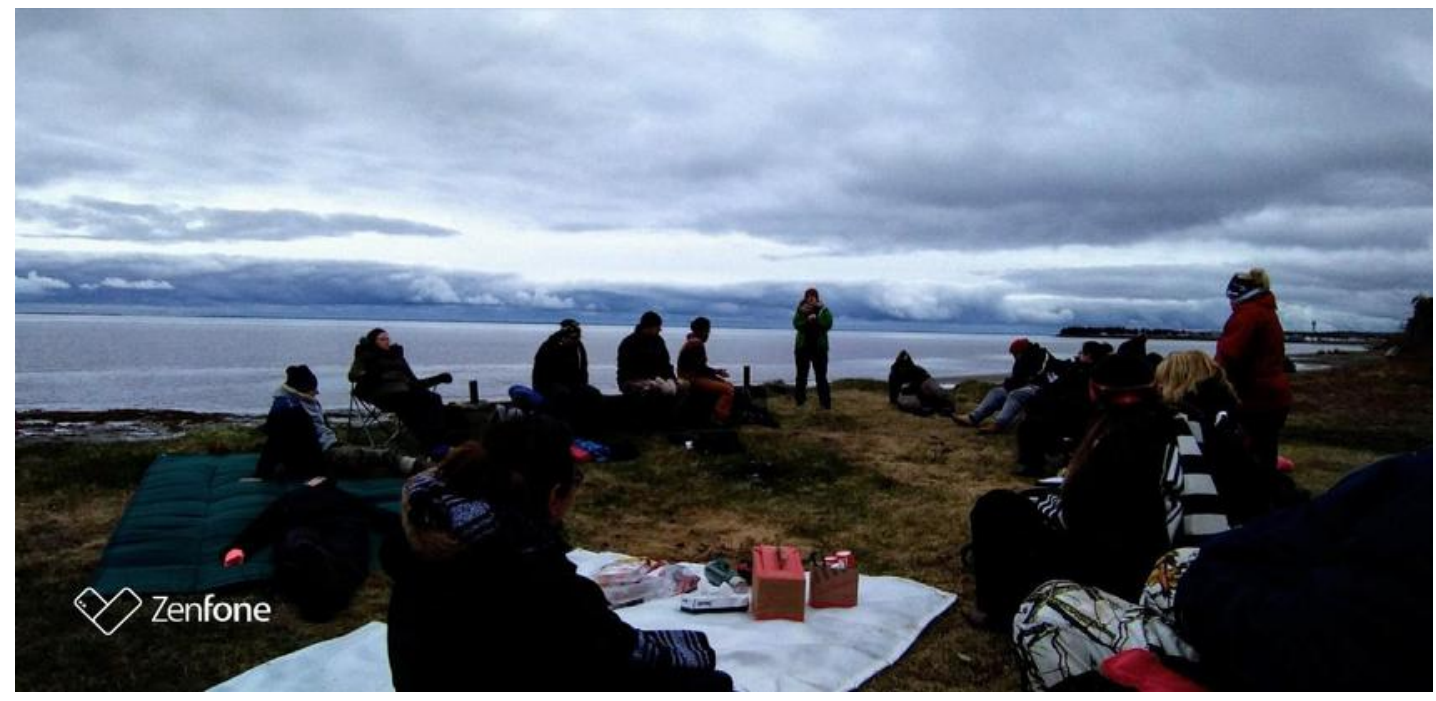

Figure 1. Three Nations Education Group Inc. educators at Esgenoopetitj First Nation pow-wow grounds during the in-person intensive portion of the FNSPC pilot.

Photo credit: Katalin Koller

\section{Appendix A: Forest and Nature School in Canada}

Forest and Nature Schools formally started in Denmark in the late 1950s and have now expanded worldwide to include Canada (Cree, 2018; CNAC, 2014; Knight, 2009; Robertson, 2008). Forest and Nature Schools employ a delivery model where children spend anywhere from a half-day to a full day outdoors in local woodlands or green spaces on a part-time or fulltime basis (CNAC, 2014). Families have traditionally accessed forest and Nature Schools with children in the early years and Kindergarten (Cree, 2018; Cree \& McCree, 2012). The defining principles of this type of nature-based education are regular and repeated access to the same natural space, as well as emergent, experiential, inquiry-based, play-based, and place-based learning (CNAC, 2014). The first Forest and Nature School in Canada was founded in 2007 by Marlene Powers in Ottawa, Ontario (MacEachren, 2013). Powers found Forest School Canada (FSC) as an education initiative of CNAC in 2012 (MacEachern, 2013). In 2020, FSC grew into a national organization with staff working to develop a Canadian Forest School model. Within Canada, there is currently no governing body or regulation ensuring best practices within Forest and Nature Schools, but CNAC is working towards an accreditation model.

In 2013, FSC offered two pilot Forest and Nature School Practitioners' Courses (FNSPC) led by Jon Cree, the Forest School Association president in the United Kingdom (MacEachren, 2013). The first FNSPCs in Canada were heavily influenced by the European model. Since the first pilot courses in 2013, the FNSPC has shifted to being delivered by trained Forest and Nature School Practitioners from Canada. The FNSPC in Canada is a five-day intensive course followed by a year of online course work mentored by a course facilitator through an online documentation platform called Storypark. 


\section{About the Authors}

Katalin Doiron Koller (corresponding author) is Acadian-Hungarian living in unceded Wolastokuk, New Brunswick, Canada. She is the owner of Earthonomical Policy Solutions and has worked with Wabanaki communities for over a decade. She is a doctoral candidate in human geography at Carleton University studying spaces of cross-cultural solidarity. Email: earthonomicalsolutions@gmail.com

Kay Rasmussen is a mixed-race woman of Indigenous and European heritage. She holds a Master of Education for Change in Environmental and Sustainability Education from Lakehead University. Kay is also an education consultant working to support Indigenous landbased education in the early years. Email: krasmussen@childnature.ca

\section{References}

Ashton, E. (2015). Troubling settlerness in early childhood curriculum development. In V. PaciniKetchabaw \& A. Taylor (Eds.), Unsettling the colonial places and spaces of early childhood education (pp. 81-97). Routledge.

Ball, J., \& Pence, A. (2006). Supporting Indigenous children's development: Community-university partnerships. UBC Press.

Battiste, M. (2013). Decolonizing education: Nourishing the learning Spirit. UBC Press.

Battiste, M., \& Henderson, J. Y. (2019). Indigenous and trans-systemic knowledge systems.

Retrieved from https://esj.usask.ca/index.php/esj/announcement/view/371

Cajete, G. (1994). Look to the mountain: An ecology of Indigenous education. Kivaki Press.

Calderon, D. (2014). Speaking back to manifest destinies: A land education-based approach to critical curriculum inquiry. Environmental Education Research, 20(1), 24-36.

Castleden, H., Morgan, V. S. \& Lamb, C. (2012). "I spent the first year drinking tea”: Exploring Canadian university researchers' perspectives on community-based research involving Indigenous Peoples. The Canadian Geographer, 56(2), 160-179. https://doi.org/10.1111/ j.1541-0064.2012.00432.x

Child and Nature Alliance of Canada (2014). Forest and Nature School in Canada: A Head,

Heart, Hands Approach to Outdoor Learning. Retrieved from

https://childnature.ca/wp-content/uploads/2017/10/FSC-Guide-1.pdf

Child and Nature Alliance of Canada. (2019). Strategic Plan 2019-2024. Retrieved from http:// childnature.ca/wp-content/uploads/2019/08/CNAC-2019-Strategic-Plan-14-Web.pdf

Cree, J. (2018). Forest School Association History. Retrieved from https://www.forestschoolassociation.org/history-of-forest-school/

Cree, J., \& McCree, M. (2012). A brief history of the roots of forest school in the UK. Horizons: Professional development for outdoor practitioners, 60, 32-34. 
Donald, D. (2009). The curriculum problem of Indigenousness: Colonial frontier logics, teacher resistances, and the acknowledgment of ethical space. Brill, 23-41.

Ermine, W. (2007). The ethical space of engagement. Indigenous Law Journal, 6(1), 193-203.

FNIGC. (2020). The First Nation Principles of OCAP. Retrieved from https://fnigc.ca/ocap

Green, J. (2014). From colonialism to reconciliation through Indigenous human rights. In J.

Green (Ed.), Indivisible - Indigenous human rights (pp. 18-42). Fernwood Publishing.

Greenwood, D. A. (2011). Why place matters: Environment, culture, and education. Handbook of Research in the Social Foundations of Education, 632-640.

Gruenewald, D. A. (2003). The best of both worlds: A critical pedagogy of place. Educational Researcher, 32(4), 3-12.

Kimmerer, R. W. (2013). Braiding sweetgrass: Indigenous wisdom, scientific knowledge, and the teachings of plants. Milkweed Editions.

Knight, S. (2009). Forest schools and outdoor learning in the early years. Sage.

Koller, K. (2015). Towards a political economy of on-reserve Indigenous education in Canada:

Problematizing Bill C-33 [Unpublished master's thesis]. Carleton University. https://doi.org/10.22215/etd/2015-11202

MacEachren, Z. (2013). The Canadian forest school movement. LEARNing Landscapes, 7(1), 219-233.

Nxumalo, F. (2019). Decolonizing place in early childhood education. Routledge.

Robertson, J. (2008). I ur och skur. Retrieved from http://creativestarlearning.co.uk

Simpson, L. B. (2017). As we have always done: Indigenous freedom through radical resistance.

University of Minnesota Press.

Smith, L. T. (1999). Decolonizing methodologies: Research and Indigenous Peoples. Zed Books.

Taylor, A. \& Pacini-Ketchabow, V. (2015). Introduction: Unsettling the colonial places and spaces of early childhood education in settler colonial societies. In V. Pacini-Ketchabaw \& A. Taylor (Eds.), Unsettling the colonial places and spaces of early childhood education (pp. 1-18). Routledge.

Tuck, E., \& Yang, K.W. (2012). Decolonization is not a metaphor. Decolonization: Indigeneity, Education \& Society, 1(1), 1-40.

Tuck, E., McKenzie, M., \& McCoy, K. (2014). Land education: Indigenous, post-colonial, and decolonizing perspectives on place and environmental education research. Environmental Education Research, 20(1), 1-12. https://doi.org/10.1080/13504622.2013.877708 